107 Royal Netherlands Institute for Sea Research

This is a postprint of:

Meer, M.T.J. van der, Benthien, A., French, K.L., Epping, E., Zondervan, I., Reichart, G.-J., Bijma, J., Sinninghe Damsté, J.S., \& Schouten, S. (2015). Large effect of irradiance on hydrogen isotope fractionation of alkenones in Emiliania huxleyi. Geochimica et Cosmochimica Acta, 160, 16-24

Published version: $\underline{\mathrm{dx} . \text { doi.org/10.1016/i.gca.2015.03.024 }}$

Link NIOZ Repository: www.vliz.be/nl/imis?module=ref\&refid=246034

[Article begins on next page]

The NIOZ Repository gives free access to the digital collection of the work of the Royal Netherlands Institute for Sea Research. This archive is managed according to the principles of the Open Access Movement, and the Open Archive Initiative. Each publication should be cited to its original source - please use the reference as presented.

When using parts of, or whole publications in your own work, permission from the author(s) or copyright holder(s) is always needed. 


\section{Large effect of irradiance on hydrogen isotope fractionation of alkenones in}

Emiliania huxleyi.

Marcel T.J. van der Meer ${ }^{1 *}$, Albert Benthien ${ }^{2}$, Katherine L. French $^{2+}$, Eric Epping ${ }^{1}$, Ingrid Zondervan $^{2}$, Gert-Jan Reichart ${ }^{1,3}$, Jelle Bijma ${ }^{2}$, Jaap S. Sinninghe Damsté ${ }^{1,3}$ and Stefan Schouten ${ }^{1,3}$

${ }^{1}$ NIOZ Royal Netherlands Institute for Sea Research, PO Box 59, 1790 AB Den Burg, The Netherlands (*corresponding author: Marcel.van.der.Meer@nioz.nl, Tel.:

+31222369568, Fax: +31222319674)

${ }^{2}$ Alfred-Wegener-Institute Helmholtz-Zentrum für Polar- und Meeresforschung, PO Box 1201 61, D-27515 Bremerhaven, Germany

${ }^{3}$ Faculty of Geosciences, Utrecht University, PO Box 80.021, 3508 TA Utrecht, The Netherlands

+ Present day address: Woods Hole Oceanographic Institution, Cambridge, MA 02139, United States 


\section{Abstract}

The hydrogen isotopic $(\delta \mathrm{D})$ composition of long-chain alkenones produced by

3 certain haptophyte algae has been suggested as a potential proxy for reconstructing

4 paleo sea surface salinity. However, environmental parameters other than salinity may

5 also affect the $\delta \mathrm{D}$ of alkenones. We investigated the impact of the level of irradiance on

6 hydrogen isotopic fractionation of alkenones versus growth water by cultivating two

7 strains of the cosmopolitan haptophyte Emiliania huxleyi at different light intensities.

8 The hydrogen isotope fractionation decreased by approximately 40\%o when irradiance

9 was increased from 15 to $200 \mu \mathrm{mol}$ photons $\mathrm{m}^{-2} \mathrm{~s}^{-1}$ above which it was relatively

10 constant. The response is likely a direct effect of photosystem I and II activity as the

11 relationship of the fractionation factor $\alpha$ versus light intensity can be described by an

12 Eilers-Peeters photosynthesis model. This irradiance effect is in agreement with

13 published $\delta \mathrm{D}$ data of alkenones derived from suspended particulate matter collected

14 from different depths in the photic zone of the Gulf of California and the eastern

15 tropical North Pacific. However, haptophyte algae tend to bloom at relatively high light

16 intensities ( $>500 \mu \mathrm{mol}$ photons $\mathrm{m}^{-2} \mathrm{~s}^{-1}$ ) occurring at the sea surface, at which hydrogen

17 isotope fractionation is relatively constant and not affected by changes in light intensity.

18 Alkenones accumulating in the sediment are likely mostly derived from these surface

19 water haptophyte blooms, when the largest amount of biomass is produced. Therefore,

20 the observed irradiance effect is unlikely to affect the applicability of the hydrogen

21 isotopic composition of sedimentary long chain alkenones as a proxy for paleosalinity.

1. Introduction 
The oxygen and hydrogen isotopic composition of ocean water is strongly

correlated with salinity because phase changes between seawater, water vapor and precipitation involves oxygen and hydrogen isotope fractionation. For instance, water vapor is depleted in ${ }^{18} \mathrm{O}$ and $\mathrm{D}$ relative to water and evaporation thus results in increased salinity and ${ }^{18} \mathrm{O}$ and $\mathrm{D}$ content of seawater in evaporative regions. The isotopically depleted water vapor will condense and precipitate over continents and thus river runoff and precipitation result in both a decrease in salinity and ${ }^{18} \mathrm{O}$ and $\mathrm{D}$ content of the seawater. Therefore, for most parts of the ocean-atmosphere interface water isotopes are linearly correlated with salinity (Craig and Gordon, 1965) and thus paleosalinity can be reconstructed from either the oxygen or hydrogen isotopic composition of water using this relation.

The hydrogen isotopic composition of water may be recorded in the nonexchangeable hydrogen in biological organic matter although with a considerable biosynthetic isotopic fractionation effect (Yakir and DeNiro, 1990; Hayes 2001). Nevertheless, as long as this fractionation can be constrained, $\delta \mathrm{D}$ analyses on marine organic matter could provide a means to reconstruct $\delta \mathrm{D}$ of seawater and, thus, if the relation between $\delta \mathrm{D}$ and salinity is known, seawater paleosalinity. Long-chain alkenones produced only by haptophyte algae such as Emiliania huxleyi (Volkman et al., 1980; Marlowe et al., 1984; Volkman et al., 1995) possess only covalently bound hydrogen atoms, which are not likely to be exchanged during diagenesis (Sessions et al., 2004), making them excellent candidate compounds for stable hydrogen isotope analysis. Initially the idea was to reconstruct paleo seawater $\delta \mathrm{D}$ directly from the measured alkenone $\delta \mathrm{D}$ assuming a fixed difference between the alkenone and water isotopic composition. This idea was motivated by the relatively constant fractionation of 
approximately $225 \%$ o between alkenones and water for batch cultures of the haptophyte Emiliania huxleyi grown on medium spiked with different levels of deuterated water, at constant salinities (Paul 2002; Englebrecht and Sachs 2005). However, experiments with E. huxleyi, and other alkenone-producing haptophytes, i.e. Gephyrocapsa oceanica, Isochrysis galbana and Chrysotila Lamellosa, cultured at different salinities showed that the biological hydrogen isotope fractionation between alkenones and water, expressed as the fractionation factor $\alpha$, depends on salinity (Schouten et al., 2006; M'Boule et al., 2014; Chivall et al., 2014). Therefore, as salinity increases not only the hydrogen isotopic composition of water increases but $\alpha$ increases as well, both resulting in an increased D content of alkenones with increasing salinity. This indicates the potential of the $\delta \mathrm{D}$ of alkenones as a paleo sea surface salinity proxy. Several studies indicate that salinity dependent hydrogen isotope fractionation might be a general phenomenon in phototrophic organisms. For instance, hydrogen isotope fractionation in cyanobacterial lipids from naturally occurring microbial mats decreases with increasing salinity (Sachse et al., 2008). The fractionation associated with dinosterol in the Chesapeake Bay estuary (Sachs and Schwab, 2011) and dinosterol and brassicasterol from saline and hypersaline lakes in North America (Nelson and Sachs, 2014) also decreased with increasing salinity.

Consequently, the hydrogen isotopic composition of $\mathrm{C}_{37}$ alkenones has been used to estimate paleo sea surface salinity (SSS) changes in the Aegean Sea at the time of sapropel S5 deposition (van der Meer et al., 2007). Here the $\delta \mathrm{D}$ record of combined $C_{37}$ alkenones $\left(C_{37: 2}\right.$ and $\left.C_{37: 3}\right)$ showed a large and abrupt shift to lower $\delta D$ values at the onset of sapropel deposition similar to the shift observed for forminiferal $\delta^{18} \mathrm{O}$ values measured on the carbonate tests of surface dwelling foraminifera (Marino et al., 2007). 
72 This shift towards more D depleted alkenones suggests that this proxy does indeed record the drop in SSS caused by the significantly increased input of freshwater from the continent at the onset of sapropel formation. The $\delta \mathrm{D}$ alkenone proxy has subsequently been used to assess paleo SSS changes in the Black Sea (van der Meer et al., 2008; Giosan et al., 2012; Coolen et al., 2013) and glacial-interglacial salinity changes in the Agulhas leakage area (Kasper et al., 2014) and Mozambique channel (Kasper et al., 2015).

Despite these successful applications of the $\delta \mathrm{D}$ alkenone proxy for the reconstruction of paleo SSS, several complications exist. Firstly, the $\delta \mathrm{D}$ of alkenones in the Chesapeake Bay estuary and from saline and hypersaline lakes in continental North America shows a correlation with the $\delta \mathrm{D}$ of the water, but does not reveal a relation of the fractionation factor $\alpha$ between alkenones and growth water with salinity as observed in for cultures (Schwab and Sachs, 2011; Nelson and Sachs, 2014). Secondly, factors other than salinity have been shown to also affect the fractionation factor $\alpha$ between alkenones and growth water. For example, E. huxleyi, G. oceanica, I. galbana and C. lamellosa all show differences in $\alpha$ at the same salinity (Schouten et al., 2006; M'Boule et al., 2014; Chivall et al., 2014) and the relationships between $\alpha$ and salinity are different for cultures harvested during different growth phases (Wolhowe et al., 2009; Chivall et al., 2014). Additionally, it has been suggested that growth rate also affects $\alpha$ (Schouten et al., 2006). A yet unexplored factor in determining hydrogen isotope fractionation is light intensity, which might have an effect because the production of NADPH, the major source of hydrogen in biosynthesis (Zhang et al., 2009), is directly linked to photosynthetic activity (Allen 2002). Here, we examined the impact of 
irradiance on the hydrogen isotope fractionation in E. huxleyi and discuss the implication of our findings for hydrogen isotopic fractionation in natural settings.

\section{Materials and methods}

\subsection{Incubation experiments}

Two sets of light experiments were carried out. Monospecific cultures of the haptophyte algae E. huxleyi (strain PML B92/11) were grown at a constant temperature of $15^{\circ} \mathrm{C}$, at a constant salinity of 32.5 , and varying light intensities of $15,30,50,100$ and $200 \mu \mathrm{mol}$ photons $\mathrm{m}^{-2} \mathrm{~s}^{-1}$. In a second experiment, batch cultures of E. huxleyi (strain RCC1238) were grown in triplicate at four different light intensities $(100,200$, 400, and $600 \mu \mathrm{mol}$ photons $\mathrm{m}^{-2} \mathrm{~s}^{-1}$ ) in autoclaved $1 \mathrm{~L}$ bottles at a constant temperature and salinity of $15^{\circ} \mathrm{C}$ and 32.2 , respectively. The two strains show similar growth responses relative to nutrients, temperature, light etc. The main difference between the two strains has to do with differences in their carbonate chemistry (Langer et al., 2009). All cultures were grown in Rumed cabinets, providing cool-white fluorescent light with a 16:8 h light:dark cycle. The seawater medium prepared according to F/2 (Guillard, 1975) for the first and F/2R for the second experiment, respectively. The enriched medium was sterile filtered using a $0.45 \mu \mathrm{m}$ filter cartridge in the first experiment and $0.2 \mu \mathrm{m}$ filter cartridge in the second experiment. All cultures were allowed to acclimate to the experimental conditions in a pre-culture before being used to inoculate the main batch cultures to provide an initial cell density between $0.5-7 \times 10^{3}$ cell ml${ }^{-1}$ for the first experiment and a target initial cell density of approximately $0.9 \times 10^{2}$ cell ml-1 for the second experiment. Cultivation took place in bottles that were closed and incubated for 4 to 12 days depending on algal growth rate. 
120 Cell numbers were log transformed and plotted versus time, growth rate $\mu\left(\mathrm{d}^{-1}\right)$ was estimated by linear regression. The cultures were harvested by filtration over ashed 0.7 $\mu \mathrm{m}$ GF/F filters (Whatman) when the cultures were in exponential growth phase and had achieved cell densities within the range of $0.55-1.5 \times 10^{5}$ cells $\mathrm{ml}^{-1}$. Filters and aliquots of the culture medium were frozen immediately and stored at $<-25^{\circ} \mathrm{C}$ until analysis. The culture waters were stored with no headspace in $12 \mathrm{~mL}$ exetainers (Labco) in the dark at $\sim 5^{\circ} \mathrm{C}$ until analysis.

\subsection{Alkenone preparation}

Filters from the first experiment were extracted ultrasonically using first methanol, followed by methanol:dichloromethane (DCM) 1:1 (v:v) and finally DCM. A ketone fraction was obtained by purifying the total lipid extracts by passing them over a silica gel cartridge (Varian Bond Elut; $1 \mathrm{~cm}^{3} / 100 \mathrm{mg}$ ), followed by saponification in 0.3 $\mathrm{mL}$ of $0.1 \mathrm{M} \mathrm{KOH}$ in methanol : water 9:1 (v/v) at $80^{\circ} \mathrm{C}$ in a capped vial for 2 hours. The alkenone containing fraction was subsequently obtained by partitioning in hexane (Benthien et al., 2002). The alkenone fractions were analyzed by gas chromatography (GC) and GC/mass spectrometry (GC/MS) (van der Meer et al., 2007). The alkenone hydrogen isotopic composition was determined by GC thermal conversion isotope ratio monitoring MS (GC/TC/irMS).

Filters from the second experiment were freeze dried for $24 \mathrm{~h}$ prior to automated

140 solvent extraction by a Dionex ASE using a 9:1 (v:v) DCM:methanol mixture. Total

141 lipid extracts (TLEs) were dried down using a rotary evaporator. The TLEs were

142 subsequently saponified by adding methanol and $1 \mathrm{ml} 0.1 \mathrm{M} \mathrm{KOH}$ and heating at $80^{\circ} \mathrm{C}$ 
143 for $2 \mathrm{~h}$. The saponified alkenone fraction was analyzed by gas chromatography with

144 flame ionization detection (GC-FID).

145

\subsection{Instrumental analysis}

The algal culture media $\delta \mathrm{D}$ water values were determined by Elemental Analysis

148 (EA)/Thermal Conversion (TC)/irmMS using a Thermo Electron EA/TC coupled to a

149 Thermo Electron DELTA ${ }^{\text {Plus }}$ XL mass spectrometer for the first experiment according to

150 Schouten et al., 2006. In short, about $1 \mu$ of water was injected into a glassy carbon

151 filled ceramic tube at a temperature of $1425{ }^{\circ} \mathrm{C}$. The $\mathrm{H}_{3}{ }^{+}$-factor was determined daily

152 and was approximately $8.0 \pm 0.3 \mathrm{ppm} \mathrm{mV}^{-1}$. Waters were analyzed with at least ten

153 replicate analyses. Hydrogen gas with a predetermined isotopic composition was used

154 as reference and the water isotope values were calibrated against in-house lab standards

155 (North Sea water: $+5 \%$ and bidistilled water: $-76 \%$ o that were calibrated by using

156 Vienna Standard Mean Ocean Water (VSMOW) and Greenland Ice Sheet Precipitation

157 (GISP) standards). The hydrogen isotopic composition of the medium used in the

158 second experiment was determined by the hydrogen gas-water equilibrium method 159 using a gas bench coupled to a Thermo Electron DELTA ${ }^{\text {Plus }}$ XP (Wong and Clarke, 160 2012) at the University of Utrecht.

161 Compound-specific hydrogen isotopic compositions for the combined $\mathrm{C}_{37}$

162 alkenones (cf. van der Meer et al., 2013) from the first experiment were measured by

163 GC/TC/irmMS using a Thermo Electron DELTA ${ }^{\text {Plus }}$ XL mass spectrometer using a

164 CPSil 5 GC column with a $0.4 \mu \mathrm{m}$ film thickness and a constant flow of He of $1 \mathrm{ml}$

$165 \mathrm{~min}^{-1}$. Compounds were converted to hydrogen gas and graphite at $1425{ }^{\circ} \mathrm{C}$ in an empty

166 ceramic tube which was pre-conditioned by injecting $0.2 \mu$ of hexane several times $(\sim 5)$ 
in the first week after installing a new reactor tube. Hydrogen gas with a predetermined

168

169

170

171

172

173

174

175

176

177

178

179

180

181

182

183

184

185

186

187

188

189 isotopic composition was used as reference gas at the beginning and end of each analytical run and a $\mathrm{C}_{16}-\mathrm{C}_{32} n$-alkanes mixture with offline determined isotopic compositions (ranging from $-42 \%$ to $-256 \%$ vs. VSMOW, Schimmelmann MixB ) was used to monitor the system performance daily. The average offsets between the measured $\delta \mathrm{D}$ values of the $\mathrm{C}_{16}-\mathrm{C}_{32} n$-alkanes and their offline determined values were generally $5 \%$ or less. Samples were analyzed at least in duplicate and the reproducibility was typically better than 5\% (Table 1). As additional control, squalane was co-injected with every analysis and the average squalane value typically was $-166 \pm$ $3 \%$, while the offline determined value was $-170 \%$.

Compound-specific hydrogen isotope values for the alkenones from the second experiment were determined by GC/TC/irmMS with a Thermo Electron DELTA ${ }^{\text {Plus }}$ XP mass spectrometer using high temperature conversion at the University of Utrecht. Compounds were converted to hydrogen gas and graphite in an empty ceramic tube heated to $1400{ }^{\circ} \mathrm{C}$. The hydrogen isotopic composition of the combined $\mathrm{C}_{37}$ alkenones was corrected using the Schimmelmann $n$-alkane mix, Mix A. A squalane standard was co-injected with every sample and its average value was $-166.3 \pm 5.1 \%$, which compared well with its offline determined value of $-169 \%$.

\subsection{Modelling}

A modified Eilers-Peeters formulation (Eilers and Peeters, 1988) was used to describe both growth rate $\mu$ and fractionation factor $\alpha$ in response to irradiance. This model can be applied directly to describe growth rate $\mu$ : 


$$
\mu=\mu_{\max } * \frac{2 *(1+\beta) * I / \text { Iopt }}{(I / \text { Iopt })^{2}+2 * \beta * I / I_{\text {Iopt }}+1}
$$

190 where $\beta$ is a shape factor and $\mu_{\max }$ represents the maximum growth rate. Growth rate $\mu$ 191 attains a maximum value at optimal irradiance $\left(I_{\text {opt }}\right)$. The shape factor $\beta$ determines the 192 'peakedness' or rounding of the production curve (e.g. Soetaert et al., 1994).

The model cannot be applied directly to describe hydrogen isotope fractionation,

194 as the $\alpha$ value does not equal zero in the dark. Therefore the basic equation was 195 extended with an offset value, $\alpha_{0}$, which defines the fractionation at zero light intensity:

$$
\alpha=\alpha_{0}+\gamma * \frac{2 *(1+\beta) * I / I_{o p t}}{\left(I / I_{o p t}\right)^{2}+2 * \beta * I / I_{o p t}+1}
$$

196 where $\alpha$ attains a maximum value at $I_{\text {opt }}$ equal to $\alpha_{\max }=\alpha_{0}+\gamma$. Parameter values $197 \mu_{\max }, \alpha_{0}, \alpha_{\max }$, and $I_{o p t}$ were estimated by minimizing the sum of squared differences between the model and experimental data using the Excel Solver routine.

\section{Results}

We analyzed the $\delta \mathrm{D}$ values of alkenones produced by E. huxleyi grown in batch cultures at different irradiance levels. For the first experiment, where E. huxleyi strain PML B92/11 was grown with light intensities ranging from 15 to $200 \mu \mathrm{mol}$ photons $\mathrm{m}^{-2}$

$204 \mathrm{~s}^{-1}$, the relationship between the growth rate and irradiance indicates that E. huxleyi is 205 growing under light limitation at light intensities $<100 \mu \mathrm{mol}$ photons $\mathrm{m}^{-2} \mathrm{~s}^{-1}$. Growth rate is approximately $0.5 \mathrm{~d}^{-1}$ at the lowest irradiance and increases to approximately 1.0 $207 \mathrm{~d}^{-1}$ at $50 \mu \mathrm{mol}$ photons $\mathrm{m}^{-2} \mathrm{~s}^{-1}$. The growth rates level off at approximately $1.1 \mathrm{~d}^{-1}$ for irradiances exceeding $100 \mu \mathrm{mol}$ photons $\mathrm{m}^{-2} \mathrm{~s}^{-1}$ (Table 1; Fig. 1). For the second experiment with E. huxleyi strain RCC1238 and irradiance levels ranging from 100 to 
$210600 \mu \mathrm{mol}$ photons $\mathrm{m}^{-2} \mathrm{~s}^{-1}$, a relatively constant growth rate of approximately $1.3 \mathrm{~d}^{-1}$ was

211 observed (Table 1; Fig. 1). The growth rates for E. huxleyi strain RCC1238 in

212 experiment 2 are slightly higher than for strain PML B92/11 in experiment 1 at the

213 corresponding irradiances of 100 and $200 \mu \mathrm{mol}$ photons $\mathrm{m}^{-2} \mathrm{~s}^{-1}$.

214 The hydrogen isotopic composition of the combined $\mathrm{C}_{37: 2}$ and $\mathrm{C}_{37: 3}$ alkenones

215 ranged from approximately $-230 \%$ at the lowest level of irradiance to

216 approximately $-189 \%$ at an irradiance of $200 \mu \mathrm{mol}$ photons $\mathrm{m}^{-2} \mathrm{~s}^{-1}$ for the first

217 experiment (Table 1). For the second experiment the isotopic composition of the

218 combined $\mathrm{C}_{37: 2}$ and $\mathrm{C}_{37: 3}$ alkenones ranged from approximately $-212 \%$ at $100 \mu \mathrm{mol}$

219 photons $\mathrm{m}^{-2} \mathrm{~s}^{-1}$ to $-188 \%$ at $200 \mu \mathrm{mol}$ photons $\mathrm{m}^{-2} \mathrm{~s}^{-1}$. At irradiance levels $>200 \mu \mathrm{mol}$

220 photons $\mathrm{m}^{-2} \mathrm{~s}^{-1}$ the $\delta \mathrm{D}$ alkenones was approximately $-193 \%$.

221 The fractionation factor $\alpha$ between the hydrogen isotopic composition of the

222 alkenones and the culture medium ranged from approximately 0.77 at the lowest level

223 of irradiance to approximately 0.82 at an irradiance $>200 \mu \mathrm{mol}$ photons $\mathrm{m}^{-2} \mathrm{~s}^{-1}$ (Table

224 1). A strong and positive linear relationship between the fractionation factor $\alpha$ and

225 irradiance is observed for the first set of experiments up to an irradiance level of 200

$226 \mu \mathrm{mol}$ photons $\mathrm{m}^{-2} \mathrm{~s}^{-1}$ (Fig. 2). For the second experiment, the fractionation factor shows

227 values similar to those of experiment 1 at corresponding irradiance levels of 100 and

$228200 \mu \mathrm{mol}$ photons $\mathrm{m}^{-2} \mathrm{~s}^{-1}$ (Fig. 2). This suggests that the two strains fractionate similarly

229 at similar irradiance levels. At light intensities exceeding $200 \mu \mathrm{mol}$ photons $\mathrm{m}^{-2} \mathrm{~s}^{-1} \alpha$

230 decreases slightly from approximately 0.815 to approximately 0.805 (Table 1 ).

231

232

4. Discussion

233

4.1 Influence of the level of irradiance on the hydrogen isotopic fractionation. 
Our culture results demonstrate that the level of irradiance affects both the growth rate of E. huxleyi (Fig. 1) and the hydrogen isotope fractionation between the alkenones produced and the water (Fig. 2). The growth rate increased linearly with irradiance up to between 50 and $100 \mu \mathrm{mol}$ photons $\mathrm{m}^{-2} \mathrm{~s}^{-1}$, and leveled off at irradiances above 100 $\mu \mathrm{mol}$ photons $\mathrm{m}^{-2} \mathrm{~s}^{-1}$. Even though the data are from experiments using two different $E$. huxleyi strains, the combined data of growth rates versus irradiance can be described by a single fit with the Eilers-Peeters model (Eq. 1) $\left(\mathrm{R}^{2}=0.89\right.$; Fig. 1). Based on these results, it seems growth of E. huxleyi is not inhibited by irradiance levels of up to 600 $242 \mu \mathrm{mol}$ photons $\mathrm{m}^{-2} \mathrm{~s}^{-1}$.

The decrease in $\alpha$ at higher irradiance levels $\left(>200 \mu \mathrm{mol}\right.$ photons $\mathrm{m}^{-2} \mathrm{~s}^{-1}$; Fig. 2$)$ is similar to what is typically observed in Photosynthesis-Irradiance curves and is typically attributed to light inhibition (e.g. Eilers and Peeters, 1988). A modified Eilers-Peeters type of equation (Eq. 2) was used to describe the observed relationship of irradiance

247 with $\alpha$, yielding a good fit $\left(\mathrm{R}^{2}=0.94\right.$; Fig. 2$)$. This fit predicts a maximum fractionation 248 factor of 0.814 at an optimum irradiance $\left(I_{\mathrm{opt}}\right)$ of approximately $310 \mu \mathrm{mol}$ photons $\mathrm{m}^{-2} \mathrm{~s}^{-}$ $249{ }^{1}$, which is in the range of saturation irradiance $\left(\mathrm{I}_{\mathrm{sat}}\right)$ values $\left(200-400 \mu \mathrm{mol}\right.$ photons $\mathrm{m}^{-2}$ $250 \mathrm{~s}^{-1}$ ) reported for photosynthesis in E. huxleyi strains (Flameling and Kromkamp, 1998; 251 Feng et al., 2008; Harris et al., 2005). However, higher and lower $\mathrm{I}_{\text {sat }}$ values have also been reported (Nanninga and Tyrrell 1996, and references therein). Because the modified Eilers-Peeters equation describes our data well, we suggest that irradiance is a major factor influencing the fractionation factor $\alpha$ between the alkenones and growth water of the haptophytes grown in our culture experiments. 
rates controlled by the level of irradiance. However, plotting the growth rate against the fractionation factor $\alpha$ for all irradiances from both experiments performed here shows no clear correlation between $\alpha$ and growth rate (Fig. 3). Fractionation factor $\alpha$ increases

261 from growth rates of 0.4 to approximately $1.2 \mathrm{~d}^{-1}$ after which it decreases a little,

262 although there is some scatter at these higher growth rates. These results suggest that in our experiments $\alpha$ does not change because of changing growth rates, but that both $\alpha$ and growth rate are a function of irradiance. These findings are different from the results of Schouten et al. (2006; Fig. 3), where E. huxleyi was grown at constant irradiance but different salinities and temperatures, suggesting that hydrogen isotope

267 fractionation in alkenone biosynthesis in these experiments is more likely controlled by 268 downstream biosynthetic effects.

A possible explanation for this effect of irradiance on the hydrogen isotopic fractionation of E. huxleyi could be the central role NADPH has as hydrogen source for 271 biosynthesis (Yakir and DeNiro, 1990; Hayes, 2001), i.e. approximately 50\% of non272 exchangeable hydrogen in lipids is derived from NADPH (Zhang et al., 2009). The 273 initial biosynthetic isotopic fractionation effect from water to the primary photosynthate 274 is considerable, ca. $171 \%$, suggested to be largely due to the reduction of $\mathrm{NADP}^{+}$to 275 NADPH (Yakir and DeNiro, 1990; reviewed by Hayes, 2001). The reduction of $276 \mathrm{NADP}^{+}$to NADPH in photosynthetic organisms is directly linked to photosystem 277 activity (Allen 2002 and references therein) and therefore potentially light intensity.

278 This probably explains the link between irradiance level and hydrogen isotopic 279 fractionation, although the exact biochemical mechanisms responsible for this irradiance depended hydrogen isotope fractionation effect is unclear and subject for future

281 research. 


\subsection{Potential implications for the natural environment.}

284

285

286

287

288

289

290

291

292

293

294

295

296

297

298

299

300

301

302

303

304

305

The magnitude of the change in $\delta \mathrm{D}_{\text {alkenones }}$ between cultures grown at 15 and 200 $\mu \mathrm{mol}$ photons $\mathrm{m}^{-2} \mathrm{~s}^{-1}\left(\sim 40 \%\right.$ or $0.2 \%$ per $\mu \mathrm{mol}$ photons $\left.\mathrm{m}^{-2} \mathrm{~s}^{-1}\right)$ is relatively large and comparable in magnitude to the change observed for cultures grown in salinities varying by $\sim 20$ salinity units (i.e. 1-3\% change per salinity unit observed in cultures; Schouten et al., 2006; M'Boule et al., 2014; Chivall et al., 2014). This suggests that an irradiance effect could be large enough to limit the applicability of $\delta \mathrm{D}_{\text {alkenones }}$ as a proxy for paleo salinity. An important constraint will be the overall in situ irradiance level during biomass formation and alkenone synthesis (Wolhowe et al., 2015), as well as how much variability in irradiance, which is related to seasonal variability and water depth, is captured by sedimentary alkenones, especially when averaged over geological time scales.

Depending on season, latitude and depth, photosynthetically available radiation in the ocean will range from 0 to approximately $810 \mu \mathrm{mol}$ photons $\mathrm{m}^{-2} \mathrm{~s}^{-1}$ (Frouin and Murakami 2007), a range almost entirely covered by our irradiance experiments. Our results show that irradiance has the strongest effect on the hydrogen isotopic fractionation at light intensities from 15 to $200 \mu \mathrm{mol}$ photons $\mathrm{m}^{-2} \mathrm{~s}^{-1}$. This irradiance effect is in agreement with $\alpha_{\text {alkenones/water }}$ in suspended particulate matter from the photic zone of the Gulf of California and the eastern tropical North Pacific which show decreasing values with increasing depth and thus decreasing light levels (Wolhowe et al., 2015).

Algae, including alkenone producing haptophytes, tend to form large blooms when the growth conditions, specifically nutrient levels, temperature and irradiance, are 
optimal. E. huxleyi, for instance, is thought to thrive under high light conditions, at mixed layer depths generally $<30$ meter (Tyrrell and Merico, 2004; Harris et al., 2005). They outcompete other algal species that suffer from photoinhibition under these conditions, a process that is apparently absent in E. huxleyi (Nanninga and Tyrrell, 310 1996). In fact, based on field data collected during E. huxleyi blooms, mesocosm studies and culture experiments, E. huxleyi is thought to only form large blooms at light intensities $>530 \mu \mathrm{mol}$ photons $\mathrm{m}^{-2} \mathrm{~s}^{-1}$ (Nanninga and Tyrrell, 1996 and references

313 therein; Harris et al., 2005). This is in the range of irradiance levels in our experiments 314 where $\alpha$ is relatively constant (Fig. 2), indicating that the $\delta \mathrm{D}$ of alkenones synthesized 315 during blooming would show only minor variation due to variations in the level of 316 irradiance. If the majority of alkenones in the sediment are derived from haptophytes 317 blooming at the surface, this indicates that variations in the level of irradiance would only have a minor effect on the $\delta \mathrm{D}$ of sedimentary alkenones . Indeed, it has been

319 shown often that the degree of unsaturation of alkenones, the $\mathrm{U}^{\mathrm{K}}{ }_{37}$, which is used as a 320 paleo sea surface temperature proxy, correlates on a global scale best with annual mean 321 sea surface temperatures rather than deeper water temperatures, i.e. at the bottom of the 322 photic zone (e.g. Müller et al., 1998). Furthermore, during bloom conditions when growth becomes limited by nutrient limitation, but photosynthesis continues as long as there is enough light, the haptophyte algae produce more alkenones per cell to store the reducing equivalents (i.e. NADPH) produced during photosynthesis ( Eltgroth et al.,

326 2005). High cell densities during bloom conditions might also promote grazing and packaging of cells and alkenones in fecal pellets, cell aggregation and increase the possibility of cell material attaching to sinking particles, increasing the transport efficiency of haptophyte cell material, including alkenones, to the underlying sediment. 
Therefore it seems likely that the majority of alkenones in the sediment are derived from haptophyte blooms and reflect high light conditions.

Nevertheless, the conditions under which the majority of the sedimentary alkenones are produced together with the environmental significance of irradiance on the hydrogen

334 isotope fractionation should be further tested in nature by sampling suspended particulate matter from different water depths (c.f. Wolhowe et al., 2015) and bloom and non-bloom derived alkenones using sediment traps and analyzing core tops from close to the equator to high latitudes to capture seasonal variability in irradiance.

\section{Conclusion}

Cultivation of two E. huxleyi strains show that when growth rate is irradiancelimited, increasing growth results in decreased hydrogen isotope fractionation, the opposite response to temperature/salinity-limited growth rate. Rather, our results suggest that irradiance is directly affecting the hydrogen isotopic fractionation of $E$.

344 huxleyi up to levels of $200 \mu \mathrm{mol}$ photons $\mathrm{m}^{-2} \mathrm{~s}^{-1}$ after which it remains relatively constant. E. huxleyi usually thrives under relatively high light conditions and is thought to bloom at light intensities $>500 \mu \mathrm{mol}$ photons $\mathrm{m}^{-2} \mathrm{~s}^{-1}$. Therefore, it seems unlikely that light affects the use of the hydrogen isotopic composition of sedimentary long chain alkenones as a proxy for paleosalinity, assuming that the majority of sedimentary alkenones are derived from surface water haptophyte blooms. The actual conditions under which most of the sedimentary alkenones are produced, together with the significance of irradiance on the hydrogen isotopic composition of long chain alkenones in natural settings should be further investigated. 
We would like to thank the associate editor, Dr. Canuel, and Dr. Sessions, Dr.

Wolhowe and two anonymous reviewers for their constructive comments. This work

was supported by the Dutch Organization for Scientific Research (NWO) through a

VIDI grant to Marcel van der Meer. A Fulbright research grant was awarded to

Katherine French to work at the AWI. Part of this work was funded by the European

Science Foundation (ESF) under the EUROCORES Programme "EuroCLIMATE",

Research, FP6. NWO is also acknowledged for supporting the Dutch part of this program. This work was carried out under the program of the Netherlands Earth System

364 Science Centre (NESSC).

365

\section{References}

367

Allen J. F. (2002) Photosynthesis of ATP-electrons, proton pumps, rotors and poise. Cell 110, 273-276.

369 Benthien A., Schulte S., Müller P. J., Schneider R. and Wefer G. (2002) Carbon isotopic composition of the $\mathrm{C}_{37: 2}$ alkenone in core top sediments of the South Atlantic Ocean: Effects of $\mathrm{CO}_{2}$ and nutrient concentrations. Global Biogeochem. Cycles 16 1012, 10.1029/2001GB001433.

373 Chivall D., M'Boule D., Sinke-Schoen D., Sinninghe Damsté J.S., Schouten S. and van

374 der Meer M. T. J. (2014) The effects of growth phase and salinity on the hydrogen

375 isotopic composition of alkenones produced by coastal haptophyte algae. Geochim.

$376 \quad$ Cosmochim. Acta 140, 381-390. 
377 Coolen M. J. L., Orsi W. D., Balkema C., Quince C., Harris K., Sylva S. P., Filipova378 Marinova M. and Giosan L. (2013) Evolution of the plankton paleome in the Black 379 Sea from the Deglacial to Anthropocene. Proc. Natl. Acad. Sci. U.S.A. 110, 8609$380 \quad 8614$.

381 Craig H. and Gordon L.I. (1965) Deuterium and oxygen 18 variations in the ocean and 382 marine atmosphere, Proceedings of a Conference on Stable Isotopes in 383 Oceanographic Studies and Paleotemperatures. Pisa: V. Lischi \& Figli., Spoleto, $384 \quad$ Italy, pp. 9 - 130.

385 Eilers P. H .C. and Peeters J. C. H. (1988) A model for the relationship between light 386 intensity and the rate of photosynthesis in phytoplankton. Ecol. Model. 42, 199-215.

387 Eltgroth M. L., Watwood R. L., Wolfe G. V. (2005) Production and cellular localization 388 of neutral long-chain lipids in the haptophyte algae Isochrysis galbana and Emiliania 389 Huxleyi. J. Phycol. 41, 1000-1009.

390 Englebrecht A. C. and Sachs J. P. (2005) Determination of sediment provenance at drift 391 sites using hydrogen isotopes and unsaturation ratios in alkenones. Geochim.

$392 \quad$ Cosmochim. Acta 69, 4253-4265.

393 Giosan L., Coolen M. J. L., Kaplan J. O., Constantinescu S., Filip F., Filipova-Marinova 394 M., Kettner A. J. and Thom N. (2012) Early anthropogenic transformation of the 395 Danube-Black Sea system. Scientific reports 2:582.

396 Guillard R. R. L. (1975) Culture of phytoplankton for feeding marine invertebrates. In 397 Culture of Marine Invertebrate Animals (eds. W. L. Smith and M. H. Chanley). 398 Plenum Press, New York. pp. 26-60.

399 Feng Y., Warner M. E., Zhang Y., Sun J., Fu F.-X., Rose J. M. and Hutchins D. A. 400 (2008) Interactive effects of increased pCO2, temperature and irradiance on the 

$87-98$.

403

404

405

Flameling I. A. and Kromkamp J. (1998) Light dependence of quantum yields for PSII charge separation and oxygen evolution in eucaryotic algae. Limnol. Oceanogr. 43, 284-297.

Frouin R. and Murakami H. (2007) Estimating Photosynthetically Available Radiation at the Ocean Surface from ADEOS-II Global Imager Data. J Oceanography 63, 493-503.

Harris G. N., Scanlan D. J. and Geider R. J. (2005) Acclimation of Emiliania huxleyi (Prymnesiophyceae) to photon flux density. J. Phycol. 41, 851-862.

Hayes J. M. (2001) Fractionation of the isotopes Carbon and Hydrogen in biosynthetic processes. In Stable Isotope Geochemistry. The Minerological Society of America, Washington. pp. 225-277.

Kasper S., van der Meer M. T. J., Mets A., Zahn R., Sinninghe Damsté J. S., and Schouten S. (2014) Salinity changes in the Agulhas leakage area recorded by stable hydrogen isotopes of $\mathrm{C}_{37}$ alkenones during Termination I and II, Clim. Past 10, 251260.

Kasper S., van der Meer M. T. J., Castañeda I. S., Tjallingii R., Brummer G.-J., Sinninghe Damsté J. S., and Schouten S. (2015) Testing the alkenone D/H ratio as a paleo indicator of sea surface salinity in a coastal ocean margin (Mozambique channel). Org. Geochem. 78, 62-68.

Langer G., Nehrke G., Probert I., Ly J. and Ziveri P. (2009) Strain-specific responses of Emiliania huxleyi to changing seawater carbonate chemistry. Biogeosciences $\mathbf{6}$, 2637-2646. 
425 Marino G., Rohling E. J., Rijpstra W. I. C., Sangiorgi F., Schouten S., and Sinninghe 426 Damsté J. S. (2007) Aegean Sea as driver of hydrographic and ecological changes in 427 the eastern Mediterranean. Geology 35, 675-678.

428 Marlowe I. T., Green J. C., Neal A. C., Brassell S. C., Eglinton G. and Course P. A. 429 (1984) Long-chain (n-C37-C39) alkenones in the Prymnesiophyceae. Distribution of 430 alkenones and other lipids and their taxonomic significance. Brit. Phycol. J. 19, 203431216.

432

433

434

435

436

437

438

439

440

441

442

443

444

445

446

447

M'Boule D., Chivall D., Sinke-Schoen D., Sinninghe Damsté J. S., Schouten S. and van der Meer, M. T. J. (2014) Salinity dependent hydrogen isotope fractionation in alkenones produced by open ocean and coastal haptophyte algae. Geochim. Cosmochim. Acta 130: 126-135.

Müller P. J., Kirst G., Ruhland G., von Storch I., Rosell-Melé A. (1998) Calibration of the alkenone paleotemperature index $\mathrm{U}_{37}{ }^{\mathrm{K}^{\prime}}$ based on core-tops from the eastern South Atlantic and the global ocean $\left(60^{\circ} \mathrm{N}-60^{\circ} \mathrm{S}\right)$. Geochim. Cosmochim. Acta 62 , 1757-1772.

Nanninga H. J. and Tyrrell T. (1996) Importance of light for formation of algal blooms by Emiliania huxleyi. Mar. Ecol. Prog. Ser. 136, 195-203.

Nelson D. B. and Sachs J. P. (2014) The influence of salinity on D/H fractionation in alkenones from saline and hypersaline lakes in continental North America. Org. Geochem. 66, 38-47.

Nelson D. B. and Sachs J. P. (2014) The influence of salinity on D/H fractionation in dinosterol and brassicasterol from globally distributed saline and hypersaline lakes. Geochim. Cosmochim. Acta 133, 325-339. 
448 Paul H. A. (2002) Application of novel stable isotope methods to reconstruct 449 paleoenvironments. Ph. D. thesis, Swiss Federal Institute of Technology, Zürich. 450 Sachs J. P. and Schwab V. F. (2011) Hydrogen isotopes in dinosterol from the $451 \quad$ Chesapeake Bay estuary. Geochim. Cosmochim. Acta 75, 444-459.

452 Sachse D. and Sachs J. P. (2008) Inverse relationship between D/H fractionation in 453 cyanobacterial lipids and salinity in Christmas Island saline ponds. Geochim. $454 \quad$ Cosmochim. Acta 72, 793-806.

455 Schouten S., Ossebaar J., Schreiber K., Kienhuis M. V. M., Langer G., Benthien A., and 456 Bijma J. (2006) The effect of temperature, salinity and growth rate on the stable 457 hydrogen isotopic composition of long chain alkenones produced by Emiliania $458 \quad$ huxleyi and Gephyrocapsa oceanica. Biogeosciences 3, 113-119.

459 Schwab V. F. and Sachs J. P. (2011) Hydrogen isotopes in individual alkenones from 460 the Chesapeake Bay estuary. Geochim. Cosmochim. Acta 75, 7552-7565.

461 Sessions A.L., Sylva S.P., Summons R.E., Hayes J.M. (2004) Isotopic exchange of 462 carbon-bound hydrogen over geologic timescales. Geochim. Cosmochim. Acta 68, $463 \quad 1545-1559$.

464 Soetaert K., Herman P. M. J. and Kromkamp J. (1994) Living in the twilight: estimating 465 net phytoplankton growth in the Westerschelde estuary (The Netherlands) by means 466 of an ecosystem model (MOSES). J. Plankton Res. 16, 1277-1301.

467 Tyrrell T. and Merico A. (2004) Emiliania hyxleyi: bloom observations and the 468 conditions that induce them. In Coccolithophores: From Molecular Processes to 469 Global Impact (eds. H.R. Thierstein and J.R. Young). Springer Science, Dordrecht, $470 \quad$ The Netherlands. pp 75-97. 
van der Meer M. T. J., Baas M., Rijpstra W. I. C., Marino G., Rohling E. J., Sinninghe Damsté J. S., and Schouten S. (2007) Hydrogen isotopic compositions of long-chain alkenones record freshwater flooding of the Eastern Mediterranean at the onset of sapropel deposition. Earth. Planet. Sci. Lett. 262, 594-600.

van der Meer M. T. J., Sangiorgi F., Baas M., Brinkhuis H., Sinninghe Damsté J. S., and Schouten S. (2008) Molecular isotopic and dinoflagellate evidence for Late Holocene freshening of the Black Sea. Earth. Planet. Sci. Lett. 267, 426-434.

van der Meer M. T. J., Benthien A., Bijma J., Schouten S. and Damste J. S. S. (2013) Alkenone distribution impacts the hydrogen isotopic composition of the $\mathrm{C}_{37: 2}$ and $\mathrm{C}_{37: 3}$ alkan-2-ones in Emiliania huxleyi. Geochim. Cosmochim. Acta 111, 162-166

Volkman J. K., Eglinton G., Corner E. D. S. and Sargent J. R. (1980) Novel unsaturated straight-chain $\mathrm{C}_{37}-\mathrm{C}_{39}$ methyl and ethyl ketones in marine sediments and a coccolithophore Emiliania huxleyi. In Advances in Organic Geochemistry, 1979 (eds. A. G. Douglas and J. R. Maxwell). Pergamon Press, Oxford. pp. 219-227.

Volkman J. K., Barrett S. M., Blackburn S. I. and Sikes E. L. (1995) Alkenones in Gephyrocapsa oceanica: Implications for studies of paleoclimate. Geochim. Cosmochim. Acta 59, 513-520.

Wolhowe M. D., Prahl F. G., Probert I., and Maldonado M. (2009) Growth phase dependent hydrogen isotopic fractionation in alkenone-producing haptophytes. Biogeosciences 6, 1681-1694.

Wolhowe M. D., Prahl F. G., Desiderio R. A., Langer G., Oviedo A. M. and Ziveri P. (2015) Alkenone $\delta \mathrm{D}$ as an ecological indicator: A culture, model, and field study of physiologically-controlled chemical and hydrogen-isotopic variation in $\mathrm{C}_{37}$ alkenones. Geochim. Cosmochim. Acta Accepted. 
Wong W. W. and Clarke L. L. (2012) A hydrogen gas-water equilibrium method produces accurate and precise stable hydrogen isotope ratio measurements in nutrition studies. J. Nutr. 142: 2057-2062.

Yakir D. and DeNiro M. J. (1990) Oxygen and hydrogen isotope fractionation during cellulose metabolism in Lemna gibba L. Plant physiol. 93, 325-32.

Zhang X., Gillespie A.L. and Sessions A. (2009) Large D/H variations in bacterial lipids reflect central metabolic pathways. Proc. Natl. Acad. Sci. U.S.A. 106: 12580-12586.

502

\section{$503 \quad$ Figure legends}

504 Figure 1: Growth rate $\mu\left(\mathrm{d}^{-1}\right)$ plotted against irradiance $I\left(\mu \mathrm{mol}\right.$ photons $\left.\mathrm{m}^{-2} \mathrm{~s}^{-1}\right)$ for both the first experiment with E. huxleyi strain PML B92/11 (•) and second experiment with strain RCC1238 (A) and the model fit using the Eilers-Peeters equation (Eq. 1) (---)(Eilers and Peeters, 1988) .

Figure 2: Fractionation factor $\alpha$ alkenones versus medium water plotted against irradiance $I$ ( $\mu \mathrm{mol}$ photons $\mathrm{m}^{-2} \mathrm{~s}^{-1}$ ) for both the first experiment with E. huxleyi strain PML B92/11 (•) and second experiment with strain RCC1238 ( $\mathbf{\Delta})$ and the model fit using a modified Eilers-Peeters equation (Eq. 2) (---)(Eilers and Peeters, 1988).

Figure 3: Fractionation factor $\alpha$ for alkenones versus medium water plotted against growth rate $\mu\left(\mathrm{d}^{-1}\right)$ for both the first with E. huxleyi strain PML B92/11 (•) and second experiment with strain $\mathrm{RCC1238}(\boldsymbol{\Delta})$ in which both $\alpha$ and $\mu$ were controlled by light intensity. Included are also the $\alpha$ and $\mu$ data from Schouten et al., 2006 (X) for E. huxleyi grown at different salinities and temperatures at a single light intensity. 
519 Table 1: Results from two culture experiments in which two strains of E. huxleyi (PML

520 B92/11 and RCC1238) were cultured at different light intensities to study the effect of

521 light intensity on hydrogen isotope fractionation. All cultures were harvested in the

522 exponential growth phase after 4 to 12 days depending on the cell numbers.

523

\begin{tabular}{|c|c|c|c|c|c|c|c|}
\hline $\begin{array}{l}\text { Irradiance } I \\
(\mu \mathrm{mol} \text { photons } \\
\left.\mathrm{m}^{-2} \mathrm{~s}^{-1}\right)\end{array}$ & $\begin{array}{l}\text { Growth rate } \mu \\
\left(\mathrm{d}^{-1}\right)\end{array}$ & $\begin{array}{l}\delta D_{\text {water }} \\
\text { (\%o vs. } \\
\text { VSMOW) }\end{array}$ & Stdev & $\begin{array}{l}\delta \mathrm{D}_{\text {alkenones }} \\
(\% \text { vs. } \\
\text { VSMOW) }\end{array}$ & Stdev & $\alpha$ & Error \\
\hline \multicolumn{8}{|l|}{$\begin{array}{l}\text { Experiment } 1 \\
\text { Strain PML } \\
\text { B92/11 }\end{array}$} \\
\hline 15 & 0.47 & -1.5 & 2.5 & -233.2 & 3.2 & 0.768 & 0.004 \\
\hline 15 & 0.48 & -2.9 & 2.2 & -229.3 & 0.1 & 0.773 & 0.002 \\
\hline 30 & 0.76 & -0.7 & 1.5 & -231.4 & 0.1 & 0.769 & 0.001 \\
\hline 30 & 0.87 & -2.0 & 2.3 & -231.8 & 2.2 & 0.770 & 0.003 \\
\hline 50 & 0.94 & -1.1 & 1.8 & -231.6 & 2.3 & 0.769 & 0.003 \\
\hline 50 & 0.95 & -0.7 & 1.4 & -218.6 & 2.3 & 0.782 & 0.003 \\
\hline 100 & 1.02 & -1.7 & 1.7 & -209.2 & 0.8 & 0.792 & 0.002 \\
\hline 100 & 1.13 & -1.3 & 2.0 & -209.5 & 0.8 & 0.792 & 0.002 \\
\hline 100 & 1.08 & -2.3 & 1.3 & -209.9 & 1.5 & 0.792 & 0.002 \\
\hline 200 & 1.05 & -2.0 & 1.4 & -186.8 & 2.4 & 0.815 & 0.003 \\
\hline 200 & 1.14 & -0.9 & 1.8 & -191.1 & 1.8 & 0.810 & 0.002 \\
\hline \multicolumn{8}{|l|}{$\begin{array}{l}\text { Experiment } 2 \\
\text { Strain } \\
\text { RCC } 1238 \\
\end{array}$} \\
\hline 100 & 1.26 & -0.3 & 1.3 & -213.6 & 2.1 & 0.787 & 0.002 \\
\hline 100 & 1.30 & 0.2 & 1.6 & -214.8 & 1.1 & 0.785 & 0.002 \\
\hline 100 & 1.28 & -1.1 & 2.1 & -209.8 & 1.8 & 0.791 & 0.002 \\
\hline 200 & 1.24 & -2.4 & 1.9 & -186.3 & 1.0 & 0.816 & 0.002 \\
\hline 200 & 1.25 & -0.7 & 0.0 & -189.8 & 1.1 & 0.811 & 0.001 \\
\hline 200 & 1.24 & -1.8 & 2.6 & -187.1 & 2.0 & 0.814 & 0.003 \\
\hline 400 & 1.24 & 1.2 & 1.3 & -192.9 & 5.0 & 0.806 & 0.005 \\
\hline 400 & 1.27 & 0.4 & 1.2 & -192.3 & 0.5 & 0.807 & 0.001 \\
\hline 400 & 1.24 & 0.3 & 1.2 & -188.5 & 5.4 & 0.811 & 0.006 \\
\hline 600 & 1.30 & -2.8 & 1.5 & -196.8 & 2.7 & 0.805 & 0.003 \\
\hline 600 & 1.32 & -0.9 & 0.2 & -196.4 & 2.9 & 0.804 & 0.003 \\
\hline 600 & 1.31 & 0.1 & 4.8 & -192.6 & 3.1 & 0.807 & 0.005 \\
\hline
\end{tabular}




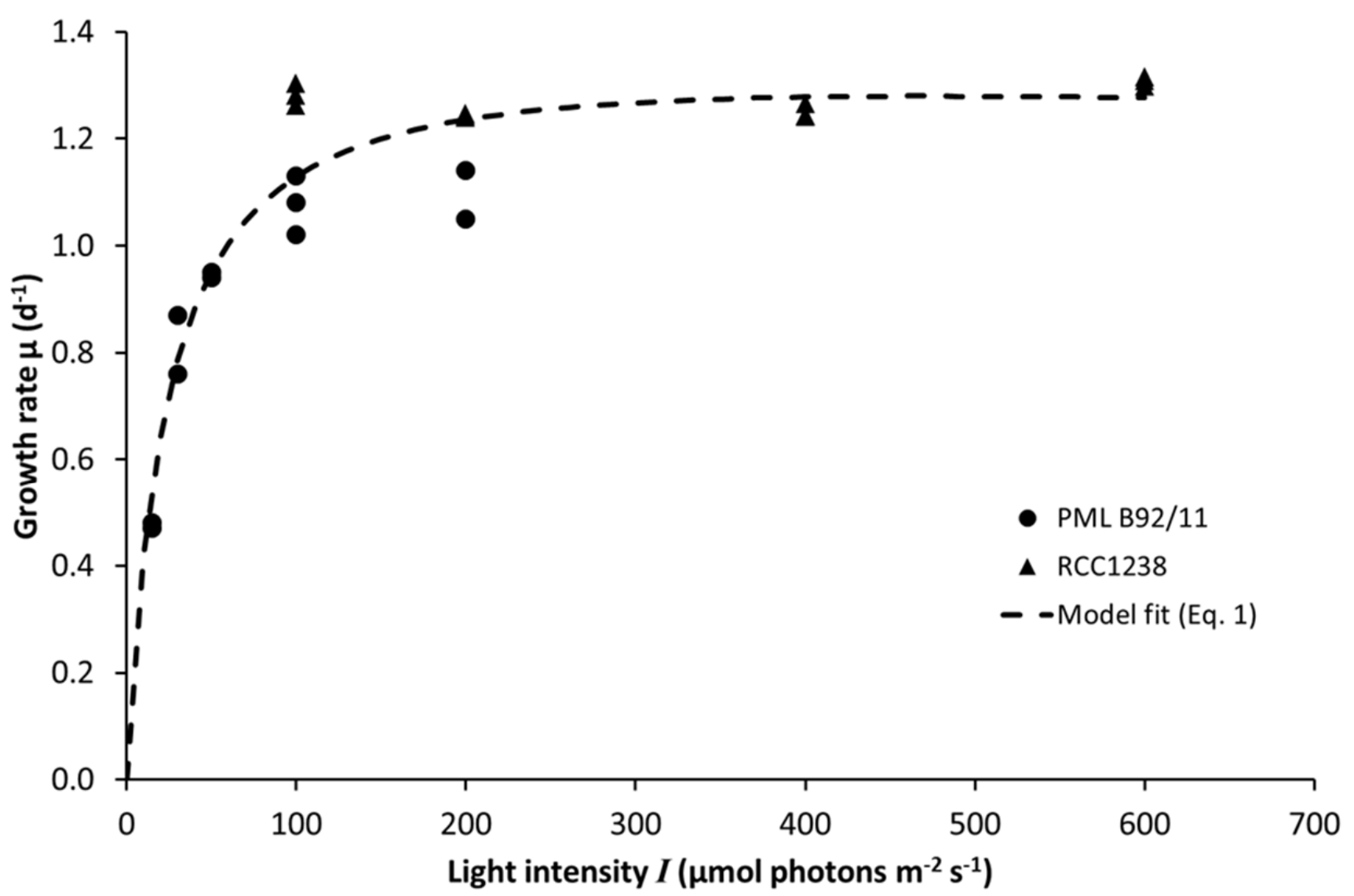

Figure 1 


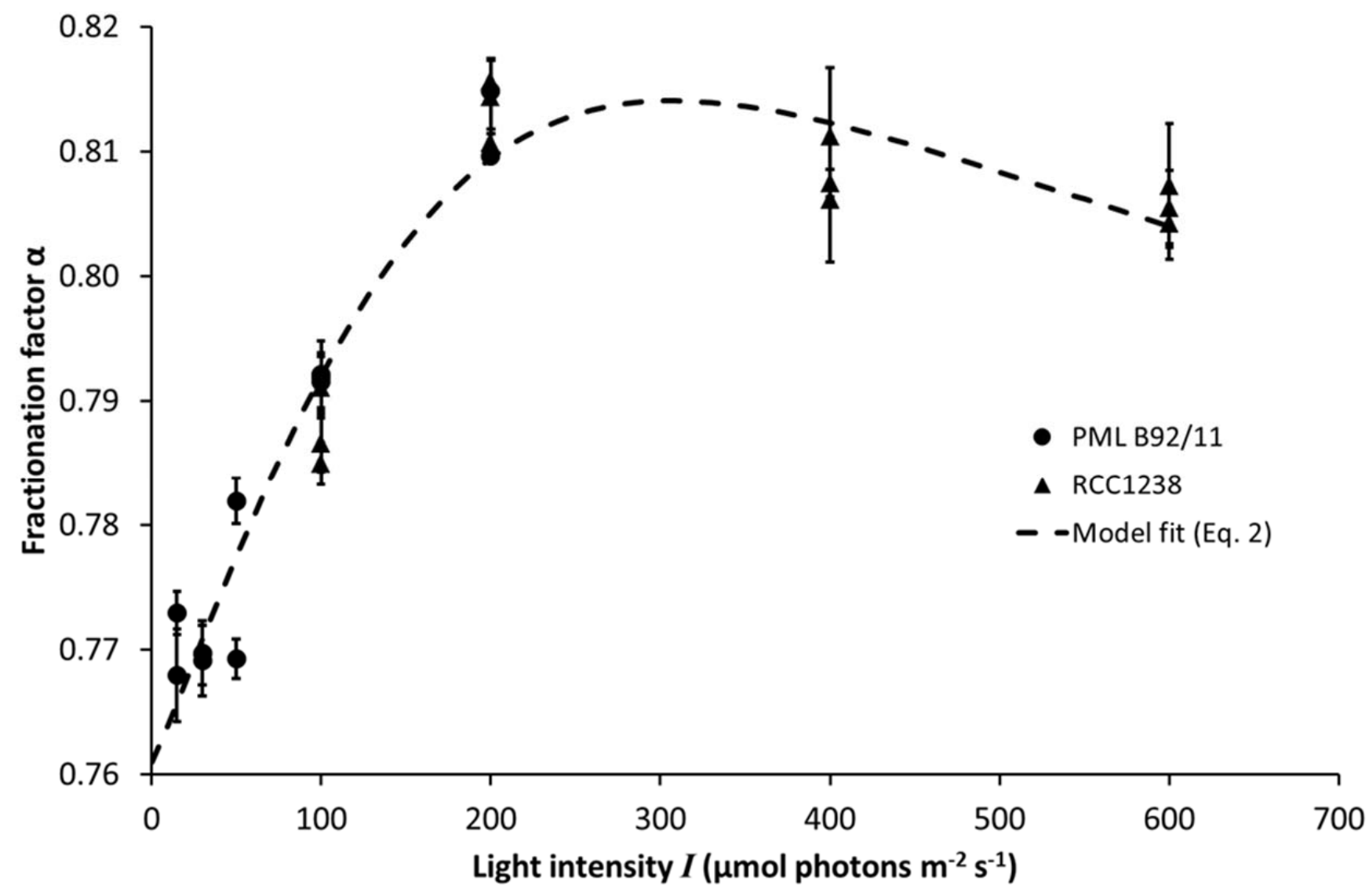

Figure 2 


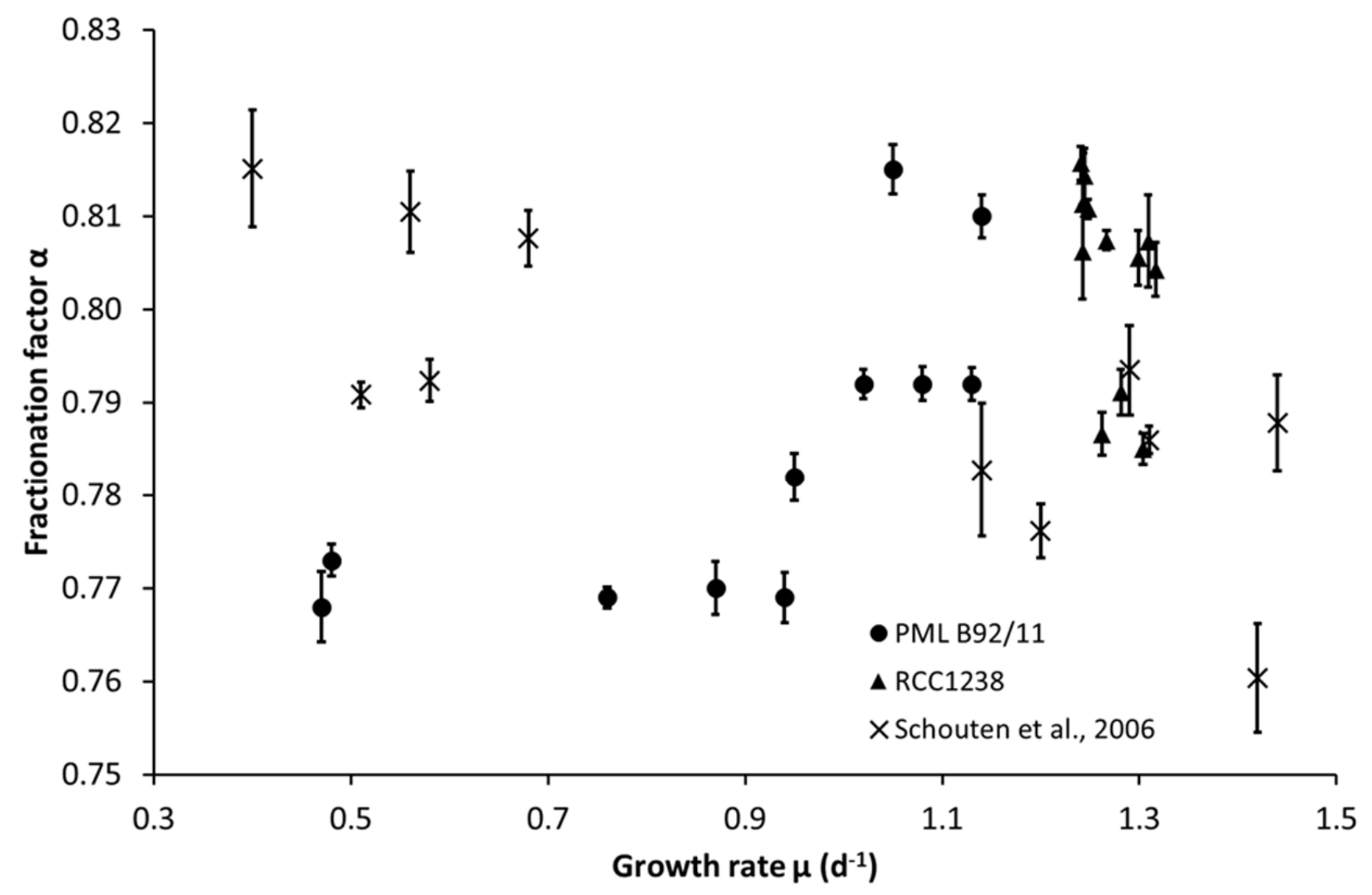

Figure 3 